\title{
Estimation of Thermodynamic Properties and Ionic Equilibria of Cobalt Chloride Solution at $298 \mathrm{~K}$
}

\author{
Man-seung Lee ${ }^{1}$ and Young-joo $\mathrm{Oh}^{2}$ \\ ${ }^{1}$ Department of Advanced Materials Science \& Engineering, Mokpo National University, Chonnam 534-729, Korea \\ ${ }^{2}$ Metal Processing Research Center, Korea Institute of Science and Technology, P.O. Box 131, Seoul, 136-791, Korea
}

\begin{abstract}
We developed a chemical model to analyze ionic equilibria in a cobalt chloride solution at $298 \mathrm{~K}$. The chemical model consisted of chemical equilibria, mass and charge balance equations. The activity coefficients of solutes and water activity were calculated with Bromley equation. Values of the equilibrium constants for the formation of cobalt chloride complexes at zero ionic strength and of the interaction parameters were estimated by applying Bromley equation to the reported equilibrium constants at different ionic strength. The effect of CoCl${ }_{2}$ and $\mathrm{HCl}$ concentrations on the distribution of cobalt species was obtained. The predicted $\mathrm{pH}$ values for $\mathrm{CoCl}-\mathrm{HCl}-\mathrm{NaOH}-\mathrm{H}_{2} \mathrm{O}$ system agreed well with those measured at $298 \mathrm{~K}$.
\end{abstract}

(Received January 13, 2004; Accepted February 24, 2004)

Keywords: $\mathrm{CoCl}_{2}, \mathrm{HCl}$, equilibrium constant, Bromley, $\mathrm{pH}$

\section{Introduction}

Cobalt is a strategically important metal as an alloying element in superalloys for aircraft engines, magnetic alloys, hard metal alloys for cutting tool and electrodeposited alloys to provide wear and corrosion-resistant metal coatings. ${ }^{1)}$ In a hydrometallurgical route for the production of cobalt, separation of cobalt and nickel is one of the most difficult operations owing to the similarities in chemical nature of the two metals. Many studies have been performed on the separation of cobalt and nickel by employing solvent extraction. $^{2,3)}$

Information of the distribution of cobalt and nickel species with the composition of a solution is valuable in choosing an extractant suitable for the separation of cobalt and nickel. In order to analyze the ionic equilibria of the mixed solution of $\mathrm{CoCl}_{2}$ and $\mathrm{NiCl}_{2}$, ionic equilibria of the respective solutions need to be developed. We reported the ionic equilibria analysis of $\mathrm{NiCl}_{2}$ solution. ${ }^{4)}$ Few studies, however, have been reported on the equilibria of cobalt chloride solution at high ionic strength.

In this study, ionic equilibria for the $\mathrm{CoCl}_{2}$ in chloride solution were analyzed by considering chemical equilibria, mass and charge balance equations. Thermodynamic properties, such as equilibrium constants for the formation of cobalt chloride complexes at zero ionic strength and interaction parameter, were estimated by applying Bromley equation to the reported equilibrium constant at different ionic strength. The activity coefficient of chemical species was also calculated with Bromley equation. ${ }^{5)}$ The validity of the ionic equilibria for the $\mathrm{CoCl}_{2}-\mathrm{HCl}-\mathrm{NaOH}-\mathrm{H}_{2} \mathrm{O}$ system at $298 \mathrm{~K}$ was verified by comparing the measured values of solution $\mathrm{pH}$ with those calculated in this study.

\section{Experimental}

Cobalt chloride solutions with different composition were prepared by dissolving $\mathrm{CoCl}_{2} \cdot 6 \mathrm{H}_{2} \mathrm{O}, \mathrm{HCl}$ and $\mathrm{NaOH}$ in distilled water. All chemicals were of reagent grade. First, known amounts of $\mathrm{CoCl}_{2} \cdot 6 \mathrm{H}_{2} \mathrm{O}, \mathrm{HCl}$ and $\mathrm{NaOH}$ were added to $50 \mathrm{~g}$ of distilled water and then the mixture was stirred with a magnetic stirrer until all the chemicals were dissolved. After all the chemicals were dissolved, the temperature of solution was controlled at $298 \mathrm{~K}$ by using a water bath. Once the temperature of the solution was stable, a $\mathrm{pH}$ of solution was measured with a $\mathrm{pH}$ meter (Orion 920A).

\section{Results and Discussion}

\subsection{Estimation of the equilibrium constant}

In chloride solution, cobalt ion forms various complexes with chloride and hydroxide ion and the complex formation reaction can be represented by

$$
\mathrm{Co}^{2+}+\mathrm{iCl}^{-}=\mathrm{CoCl}_{i}^{2-i}
$$

The equilibrium constant for eq. (1) at a given ionic strength, $K_{i}^{\mathrm{I}}$, is related to the equilibrium constant at zero ionic strength, $K_{i}^{0}$, and to the activity coefficient ratio as follows

$$
K_{i}^{0}=K_{i}^{\mathrm{I}} \frac{\gamma_{\mathrm{CoCl}_{i}^{2-i}}}{\gamma_{\mathrm{Co}^{2+}}\left(\gamma_{\mathrm{Cl}^{-}}\right)^{i}}
$$

By taking logarithm on both sides of the above equation, it is rearranged as

$$
\log K_{i}^{\mathrm{I}}=\log K_{i}^{0}+\log \gamma_{\mathrm{Co}^{2+}}+i \log \gamma_{\mathrm{Cl}^{-}}-\log \gamma_{\mathrm{CoCl}_{i}^{2-i}}
$$

The activity coefficient of solute was calculated by the Bromley equation. The Bromley equation for the activity coefficient of the cation, $\gamma_{\mathrm{M}}$, is represented by the following equations. 5)

$$
\begin{aligned}
\log \gamma_{\mathrm{M}} & =-\frac{0.5108\left(z_{\mathrm{M}}\right)^{2} I^{0.5}}{1+I^{0.5}}+F_{\mathrm{M}}=-A\left(z_{\mathrm{M}}\right)^{2}+F_{\mathrm{M}} \\
F_{\mathrm{M}} & =\sum_{\mathrm{X}}\left[\frac{\left(0.06+0.6 B_{\mathrm{MX}}\right) \times\left|z_{\mathrm{M}} z_{\mathrm{X}}\right|}{\left(1+\frac{1.5}{\left|z_{\mathrm{M}} z_{\mathrm{X}}\right|} I\right)^{2}}+B_{\mathrm{MX}}\right]
\end{aligned}
$$




$$
\times \frac{\left(\left|z_{M}\right|+\left|z_{X}\right|\right)^{2}}{4}[X]
$$

In the above equations, $z$ is ionic charge and $I$ ionic strength of solution and $B_{\mathrm{MX}}$ the interaction parameter between cation $\mathrm{M}$ and anion $\mathrm{X}$.

Substitution of the expression for the activity coefficient of each species into eq. (3) gives

$$
\begin{aligned}
\log K_{i}^{\mathrm{I}}= & \log K_{i}^{0}+\left(i^{2}-5 i\right) A \\
& +F_{\mathrm{Co}^{2+}}+i F_{\mathrm{Cl}^{-}}-F_{\mathrm{CoCl}^{2-i}}
\end{aligned}
$$

Table 1 represents the equilibrium constants for the formation of cobalt chloride complexes at different $\mathrm{HClO}_{4}$ concentration. ${ }^{6)}$ The concentrations of $\mathrm{Co}^{2+}, \mathrm{Cl}^{-}$and $\mathrm{CoCl}_{i}{ }^{2-i}$ are negligible compared to the $\mathrm{HClO}_{4}$ concentration in these studies. ${ }^{7,8)}$ Hence, $F$ term for the activity coefficient
Table 1 Reported values for the logarithm of equilibrium constant at a series of ionic strength with $\mathrm{HClO}_{4}$ as the inert salt at $298 \mathrm{~K}$.

\begin{tabular}{cccccc}
\hline Reaction & $\begin{array}{c}\log K^{\mathrm{I}} \\
(\mathrm{I}=5)\end{array}$ & $\begin{array}{c}\log K^{\mathrm{I}} \\
(\mathrm{I}=7)\end{array}$ & $\begin{array}{c}\log K^{\mathrm{I}} \\
(\mathrm{I}=8)\end{array}$ & $\begin{array}{c}\log K^{\mathrm{I}} \\
(\mathrm{I}=9)\end{array}$ & $\begin{array}{c}\log K^{\mathrm{I}} \\
(\mathrm{I}=10)\end{array}$ \\
\hline $\mathrm{Co}^{2+}+\mathrm{Cl}^{-}=\mathrm{CoCl}^{+}$ & 0.04 & 0.23 & 0.40 & 0.64 & 0.82 \\
$\mathrm{Co}^{2+}+2 \mathrm{Cl}^{-}=\mathrm{CoCl}_{2}{ }^{\circ}$ & -0.62 & -0.15 & 0.30 & 0.78 & 1.26 \\
$\mathrm{Co}^{2+}+3 \mathrm{Cl}^{-}=\mathrm{CoCl}_{3}{ }^{-}$ & -1.40 & -0.70 & 0.02 & 0.80 & 1.60 \\
$\mathrm{Co}^{2+}+4 \mathrm{Cl}^{-}=\mathrm{CoCl}_{4}{ }^{2-}$ & - & - & -0.9 & 0.2 & 1.4 \\
\hline
\end{tabular}

of the anion is related only to the cation $\mathrm{H}^{+}$of the ionic medium, while $F$ term for the activity coefficient of cation is related to the anion $\mathrm{ClO}_{4}{ }^{-}$of the ionic medium. ${ }^{7,8)}$ In this case, $F$ terms for $\mathrm{Co}^{2+}, \mathrm{Cl}^{-}$and $\mathrm{CoCl}^{+}$could be represented by

$$
\begin{aligned}
F_{\mathrm{Co}^{2+}} & =\left[\frac{2\left(0.06+0.6 B_{\mathrm{Co}^{2+}, \mathrm{ClO}_{4}^{-}}\right)}{\left(1+\frac{1.5}{2} I\right)^{2}}+B_{\mathrm{CO}^{2+}, \mathrm{ClO}_{4}^{-}}\right] \times \frac{3^{2}}{4}\left[\mathrm{ClO}_{4}^{-}\right] \\
F_{\mathrm{Cl}^{-}} & =\left[\frac{\left(0.06+0.6 B_{\mathrm{H}^{+}, \mathrm{Cl}^{-}}\right)}{(1+1.5 I)^{2}}+B_{\mathrm{H}^{+}, \mathrm{Cl}^{-}}\right] \times \frac{2^{2}}{4}\left[\mathrm{H}^{+}\right] \\
F_{\mathrm{CoCl}^{+}} & =\left[\frac{\left(0.06+0.6 B_{\mathrm{CoCl}^{+}, \mathrm{ClO}_{4}^{-}}\right)}{(1+1.5 I)^{2}}+B_{\mathrm{CoCl}^{+}, \mathrm{ClO}_{4}^{-}}\right] \times \frac{2^{2}}{4}\left[\mathrm{ClO}_{4}^{-}\right]
\end{aligned}
$$

Substitution of eqs. (7)-(9) into eq. (6) results in

$$
\begin{aligned}
\log K_{i}^{\mathrm{I}}= & \log K_{i}^{0}-4 A+\left[\frac{2\left(0.06+0.6 B_{\mathrm{Co}^{2+}, \mathrm{ClO}_{4}^{-}}\right)}{\left(1+\frac{1.5}{2} I\right)^{2}}+B_{\mathrm{Co}^{2+}, \mathrm{ClO}_{4}^{-}}\right] \\
& \times \frac{9}{4}\left[\mathrm{ClO}_{4}^{-}\right]+\left[\frac{\left(0.06+0.6 B_{\mathrm{H}^{+}, \mathrm{Cl}^{-}}\right)}{(1+1.5 I)^{2}}+B_{\mathrm{H}^{+}, \mathrm{Cl}^{-}}\right] \times\left[\mathrm{H}^{+}\right] \\
& -\left[\frac{\left(0.06+0.6 B_{\mathrm{CoCl}^{+}, \mathrm{ClO}_{4}^{-}}\right)}{(1+1.5 I)^{2}}+B_{\mathrm{CoCl}^{+}, \mathrm{ClO}_{4}^{-}}\right] \times\left[\mathrm{ClO}_{4}^{-}\right]
\end{aligned}
$$

Bromley reported interaction parameters between $\mathrm{Co}^{2+}$ and $\mathrm{ClO}_{4}{ }^{-}$and between $\mathrm{H}^{+}$and $\mathrm{ClO}_{4}{ }^{-}$. The values reported by Bromley and the concentrations of $\mathrm{H}^{+}$and $\mathrm{ClO}_{4}{ }^{-}$were inserted into eq. (10). This operation leaded to equations with

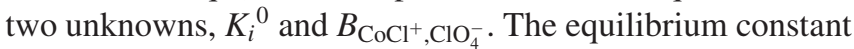
for the formation of $\mathrm{CoCl}^{+}$at zero ionic strength and the interaction parameter between $\mathrm{CoCl}^{+}$and $\mathrm{ClO}_{4}{ }^{-}$were estimated by least square of these equations. Table 2 represents the equilibrium constants and interaction parameters thus obtained in this study. Since this method could not be applied to $\mathrm{CoCl}_{2}{ }^{\circ}$ of zero charge, the equilibrium constant for the formation of $\mathrm{CoCl}_{2}{ }^{\circ}$ was obtained from literature. ${ }^{9)}$

Table 2 Estimated equilibrium constant and interaction parameter at 298 K.

\begin{tabular}{lcccc}
\hline Reaction & $\log K^{\circ}$ & Interaction parameter & & $R^{2}$ \\
\hline $\mathrm{Co}^{2+}+\mathrm{Cl}^{-}=\mathrm{CoCl}^{+}$ & 0.22 & $B_{\mathrm{CoCl}^{+}, \mathrm{ClO}_{4}^{-}}$ & 0.43 & 0.99 \\
$\mathrm{Co}^{2+}+3 \mathrm{Cl}^{-}=\mathrm{CoCl}_{3}{ }^{-}$ & -3.02 & $B_{\mathrm{H}^{+}, \mathrm{CoCl}_{3}^{-}}$ & 0.25 & 0.84 \\
$\mathrm{Co}^{2+}+4 \mathrm{Cl}^{-}=\mathrm{CoCl}_{4}{ }^{2-}$ & -9.06 & $B_{\mathrm{H}^{+}, \mathrm{CoCl}_{4}^{2-}}$ & -0.05 & 0.95 \\
\hline
\end{tabular}

Table 3 represents the equilibrium constants used in this study for the formation of various complexes together with the references. Free energy changes for the formation of $\mathrm{Co}^{2+}, \mathrm{Cl}^{-}$and $\mathrm{CoCl}^{+}$reported by Russian Academy of Science are listed in Table $4 .{ }^{10)}$ The equilibrium constant for the formation of $\mathrm{CoCl}^{+}$was calculated by inserting the thermodynamic data in Table 4 into the following equation.

$$
\Delta G^{\circ}=-R T \ln K .
$$

The logarithm of equilibrium constant thus calculated was 0.401 . This indicates that the calculated equilibrium constant agrees well with the value estimated in this study.

The interaction parameter of $\mathrm{CoCl}^{+}$was calculated from the $B_{\mathrm{CoCl}^{+}, \mathrm{ClO}_{4}^{-}}$by inserting the interaction parameter of $\mathrm{ClO}_{4}{ }^{-}$reported by Bromley into the following equation.

$$
B_{\mathrm{CoCl}^{+}, \mathrm{ClO}_{4}^{-}}=B_{\mathrm{CoCl}^{+}}+B_{\mathrm{ClO}_{4}^{-}}
$$

Activity coefficients of electrically neutral species could not be calculated with the Bromley equation. Consequently the activity coefficient of $\mathrm{CoCl}_{2}{ }^{\circ}$ was assumed to be unity. 
Table 3 Thermodynamic equilibrium constant for the formation of complexes.

\begin{tabular}{lcc}
\hline \multicolumn{1}{c}{ Reaction } & $\log K$ & Reference \\
\hline $\mathrm{H}^{+}+\mathrm{OH}^{-}=\mathrm{H}_{2} \mathrm{O}$ & 14.0 & 6 \\
$\mathrm{Co}^{2+}+\mathrm{Cl}^{-}=\mathrm{CoCl}^{+}$ & 0.22 & obtained in this study \\
$\mathrm{Co}^{2+}+2 \mathrm{Cl}^{-}=\mathrm{CoCl}_{2}{ }^{\circ}$ & -3.95 & 9 \\
$\mathrm{Co}^{2+}+3 \mathrm{Cl}^{-}=\mathrm{CoCl}_{3}{ }^{-}$ & -3.02 & obtained in this study \\
$\mathrm{Co}^{2+}+4 \mathrm{Cl}^{-}=\mathrm{CoCl}_{4}{ }^{2-}$ & -9.06 & obtained in this study \\
$\mathrm{Co}^{2+}+\mathrm{OH}^{-}=\mathrm{CoOH}^{+}$ & 4.3 & 6 \\
$\mathrm{Co}^{2+}+2 \mathrm{OH}^{-}=\mathrm{Co}^{2}(\mathrm{OH})_{2}{ }^{\circ}$ & 8.4 & 6 \\
$2 \mathrm{Co}^{2+}+\mathrm{OH}^{-}=\mathrm{Co}_{2} \mathrm{OH}$ & 6 \\
$4 \mathrm{Co}^{2+}+4 \mathrm{OH}^{-}=\mathrm{Co}_{4}(\mathrm{OH})_{4}{ }^{4+}$ & 2.7 & 6 \\
\hline
\end{tabular}

Table 4 Free energy change for the formation of $\mathrm{Co}^{2+}, \mathrm{Cl}^{-}$and $\mathrm{CoCl}^{+}$ reported by Russian Academy of Science.

\begin{tabular}{lc}
\hline & $\Delta G_{\mathrm{f}}{ }^{\circ}(\mathrm{kJ} / \mathrm{mol})$ \\
\hline $\mathrm{Co}^{2+}$ & -53.64 \\
$\mathrm{Cl}^{-}$ & -131.265 \\
$\mathrm{CoCl}^{+}$ & -187.192 \\
\hline
\end{tabular}

\subsection{Ionic equilibria analysis}

Mass balance equations for chloride and cobalt were obtained from the above chemical equilibria as follows:

$$
\begin{aligned}
{[\mathrm{Cl}]_{\mathrm{t}}=} & 2\left[\mathrm{CoCl}_{2}\right]_{\mathrm{t}}+[\mathrm{HCl}]_{\mathrm{t}}=\left[\mathrm{Cl}^{-}\right]+\left[\mathrm{CoCl}^{+}\right] \\
& +2\left[\mathrm{CoCl}_{2}{ }^{\circ}\right]+3\left[\mathrm{CoCl}_{3}{ }^{-}\right]+4\left[\mathrm{CoCl}_{4}{ }^{2-}\right] \\
{[\mathrm{Co}]_{\mathrm{t}}=} & {\left[\mathrm{CoCl}_{2}\right]_{\mathrm{t}}=\left[\mathrm{Co}^{2+}\right]+\left[\mathrm{CoCl}^{+}\right]+\left[\mathrm{CoCl}_{2}{ }^{\circ}\right] } \\
& +\left[\mathrm{CoCl}_{3}{ }^{-}\right]+\left[\mathrm{CoCl}_{4}{ }^{2-}\right]+\left[\mathrm{CoOH}^{+}\right] \\
& +\left[\mathrm{Co}(\mathrm{OH})_{2}{ }^{\circ}\right]+2\left[\mathrm{Co}_{2} \mathrm{OH}^{3+}\right] \\
& +4\left[\mathrm{Co}_{4}(\mathrm{OH})_{4}{ }^{4+}\right] \\
{[\mathrm{Na}]_{\mathrm{t}}=} & {[\mathrm{NaOH}]_{\mathrm{t}}=\left[\mathrm{Na}^{+}\right] }
\end{aligned}
$$

Where subscript $\mathrm{t}$ represents the total concentration.

The following charge balance equation was obtained from electroneutrality condition.

$$
\begin{aligned}
& {\left[\mathrm{H}^{+}\right]+2\left[\mathrm{Co}^{2+}\right]+\left[\mathrm{CoCl}^{+}\right]+\left[\mathrm{CoOH}^{+}\right]+3\left[\mathrm{Co}_{2} \mathrm{OH}^{3+}\right]} \\
& +4\left[\mathrm{Co}_{4}(\mathrm{OH})_{4}^{4+}\right]+\left[\mathrm{Na}^{+}\right] \\
& =\left[\mathrm{Cl}^{-}\right]+\left[\mathrm{CoCl}_{3}{ }^{-}\right]+2\left[\mathrm{CoCl}_{4}{ }^{2-}\right]+\left[\mathrm{OH}^{-}\right]
\end{aligned}
$$

In $\mathrm{CoCl}_{2}-\mathrm{HCl}-\mathrm{NaOH}-\mathrm{H}_{2} \mathrm{O}$ system, there were 13 solutes in the equilibrium state, i.e., $\left[\mathrm{Cl}^{-}\right],\left[\mathrm{Co}^{2+}\right],\left[\mathrm{CoCl}^{+}\right],\left[\mathrm{CoCl}_{2}^{\circ}\right]$, $\left[\mathrm{CoCl}_{3}{ }^{-}\right],\left[\mathrm{CoCl}_{4}{ }^{2-}\right],\left[\mathrm{CoOH}^{+}\right],\left[\mathrm{Co}(\mathrm{OH})_{2}{ }^{\circ}\right],\left[\mathrm{Co}_{2} \mathrm{OH}^{3+}\right]$, $\left[\mathrm{Co}_{4}(\mathrm{OH})_{4}{ }^{4+}\right],\left[\mathrm{H}^{+}\right],\left[\mathrm{Na}^{+}\right],\left[\mathrm{OH}^{-}\right]$. In order to calculate the equilibrium concentrations and activity coefficients of these 13 solutes and the activity of water, 27 independent equations were needed. These equations were obtained from 9 chemical equilibria shown in Table 3, 3 mass balance and charge balance, 13 activity coefficient equations of solutes and activity equation of water. These nonlinear equations were solved by Newton-Raphson method.

Table 5 shows the experimental compositions of $\mathrm{CoCl}_{2}$ $\mathrm{HCl}-\mathrm{NaOH}-\mathrm{H}_{2} \mathrm{O}$ system together with $\mathrm{pH}$ values experimentally measured at $25^{\circ} \mathrm{C}$. Also $\mathrm{pH}$ values and the ionic strength calculated in this study are shown in Table 5. Both measured
Table 5 Experimental conditions and calculated values of $\mathrm{pH}$ and ionic strength. (The unit of concentration was molality)

\begin{tabular}{rcccccc}
\hline $\mathrm{N}$ & {$\left[\mathrm{CoCl}_{2}\right]_{\mathrm{t}}$} & {$[\mathrm{HCl}]_{\mathrm{t}}$} & {$[\mathrm{NaOH}]_{\mathrm{t}}$} & \multicolumn{1}{c}{$\mathrm{pH}$} & \multicolumn{1}{c}{$\mathrm{pH}_{\mathrm{C}}$} & $\mathrm{I}_{\mathrm{C}}$ \\
\hline 1 & 0.1 & 0.1 & 0 & 1.20 & 1.14 & 0.38 \\
2 & 0.1 & 0.5 & 0.4 & 1.09 & 1.12 & 0.78 \\
3 & 1.0 & 0.5 & 0.4 & 0.80 & 0.97 & 3.29 \\
4 & 1.0 & 1.0 & 0.5 & 0.12 & 0.21 & 3.80 \\
5 & 1.0 & 1.0 & 0.8 & 0.68 & 0.61 & 3.81 \\
6 & 1.0 & 2.0 & 0.5 & -0.26 & -0.40 & 4.79 \\
7 & 1.0 & 2.0 & 1.0 & -0.19 & -0.22 & 4.81 \\
8 & 1.0 & 2.0 & 1.7 & 0.49 & 0.30 & 4.84 \\
9 & 1.0 & 2.0 & 2.3 & 5.78 & 5.32 & 5.00 \\
10 & 2.0 & 0.5 & 0.4 & 0.68 & 0.73 & 6.13 \\
11 & 2.0 & 1.0 & 0.5 & -0.20 & -0.03 & 6.57 \\
12 & 2.0 & 1.0 & 1.1 & 5.34 & 5.19 & 6.67 \\
13 & 2.0 & 2.0 & 0.5 & -0.50 & -0.63 & 7.24 \\
14 & 2.0 & 2.0 & 1.0 & -0.43 & -0.45 & 7.32 \\
15 & 2.0 & 2.0 & 1.7 & 0.27 & 0.06 & 7.43 \\
16 & 2.0 & 2.0 & 2.3 & 5.12 & 5.09 & 7.63 \\
17 & 3.0 & 1.0 & 0.5 & -0.18 & -0.23 & 8.58 \\
18 & 3.0 & 1.0 & 0.8 & 0.11 & 0.16 & 8.67 \\
19 & 3.0 & 1.0 & 1.1 & 4.90 & 4.97 & 8.81 \\
\hline & & & & & &
\end{tabular}

(N: number,

$\mathrm{pH}$ : measured values of $\mathrm{pH}$,

$\mathrm{pH}_{\mathrm{C}}$ : values of $\mathrm{pH}$ calculated in this study,

$\mathrm{I}_{\mathrm{C}}$ : values of ionic strength calculated in this study)

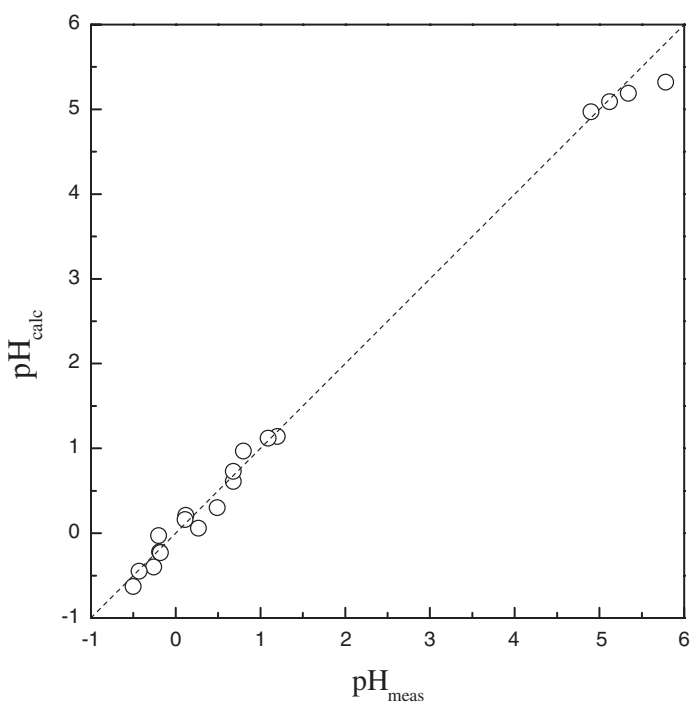

Fig. 1 Comparison of $\mathrm{pH}$ values between measured and calculated in this study.

and calculated $\mathrm{pH}$ values are shown in Fig. 1. From Table 5 and Fig. 1, it is known that the experimental $\mathrm{pH}$ values are in good agreement with the calculated values in the experimental ranges considered in this study. This verifies that not only the Bromley equation but also the thermodynamic properties of cobalt chloride obtained in this study were applicable to cobalt chloride solutions.

Figures 2 and 3 show the distribution of cobalt chloride and hydroxide complexes with $\mathrm{CoCl}_{2}$ concentration in the absence of $\mathrm{HCl}$. It is seen in Fig. 2 that most of cobalt exist as 


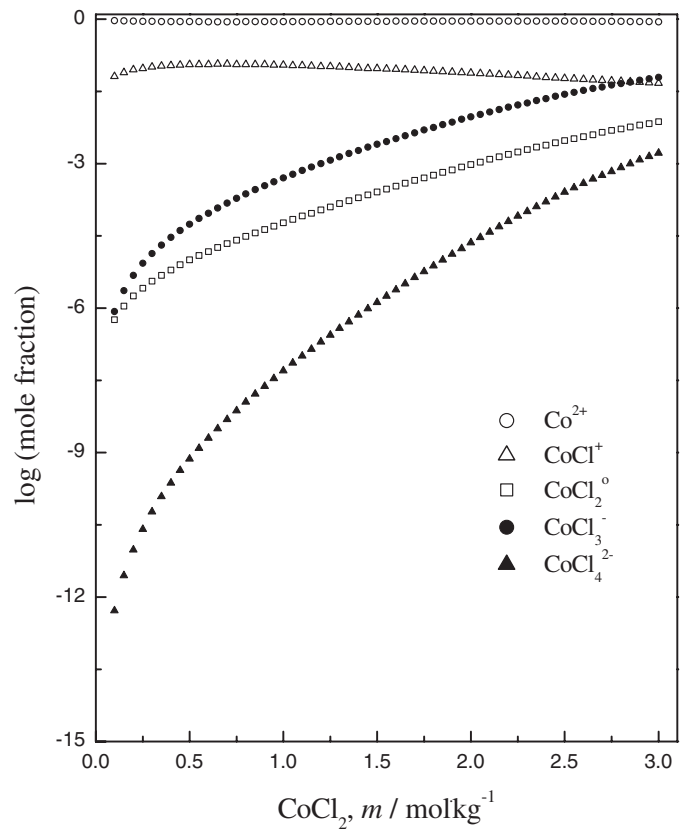

Fig. 2 Distribution of cobalt chloride complexes with the concentration of $\mathrm{CoCl}_{2}$ in the absence of $\mathrm{HCl}$.

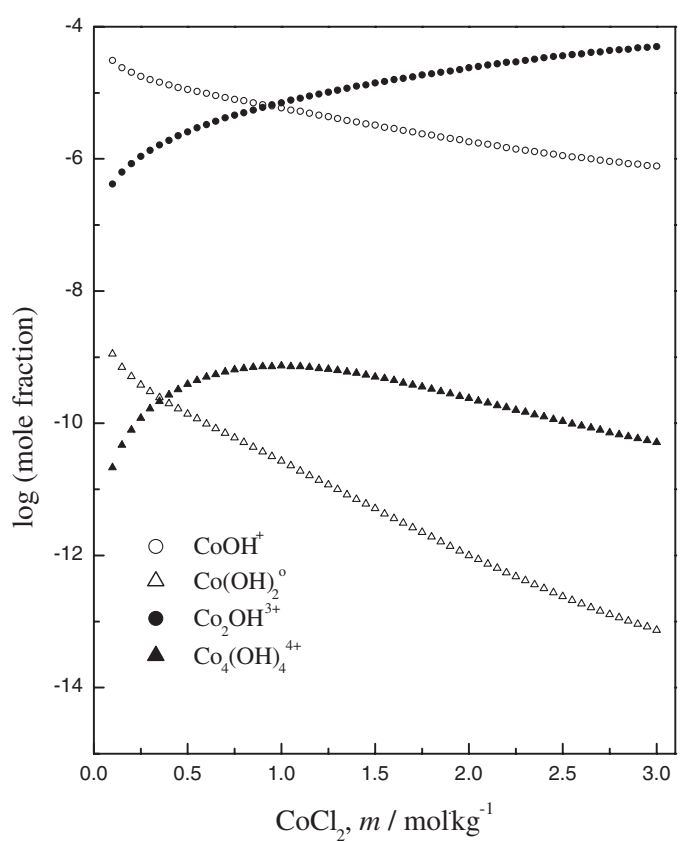

Fig. 3 Distribution of cobalt hydroxide complexes with the concentration of $\mathrm{CoCl}_{2}$ in the absence of $\mathrm{HCl}$.

$\mathrm{Co}^{2+}$ in the concentration range of up to $3 \mathrm{~m} \mathrm{CoCl}_{2}$. As the $\mathrm{CoCl}_{2}$ concentration increased, the mole fraction of $\mathrm{CoCl}_{2}{ }^{\circ}$, $\mathrm{CoCl}_{3}{ }^{-}$and $\mathrm{CoCl}_{4}{ }^{2-}$ greatly increased while that of $\mathrm{CoCl}^{+}$ remained constant. The mole fraction of $\mathrm{CoOH}^{+}$and $\mathrm{Co}(\mathrm{OH})_{2}{ }^{\circ}$ decreased with an increase in the $\mathrm{CoCl}_{2}$ concentration while that of $\mathrm{Co}_{3} \mathrm{OH}^{3+}$ increased. The mole fraction of $\mathrm{Co}_{4}(\mathrm{OH})_{4}{ }^{4+}$ increased with $\mathrm{CoCl}_{2}$ concentration and then decreased gradually with a further increase in the $\mathrm{CoCl}_{2}$ concentration after reached a maximum. By comparing Figs. 2 and 3, it is known that the mole fractions of $\mathrm{CoOH}^{+}$

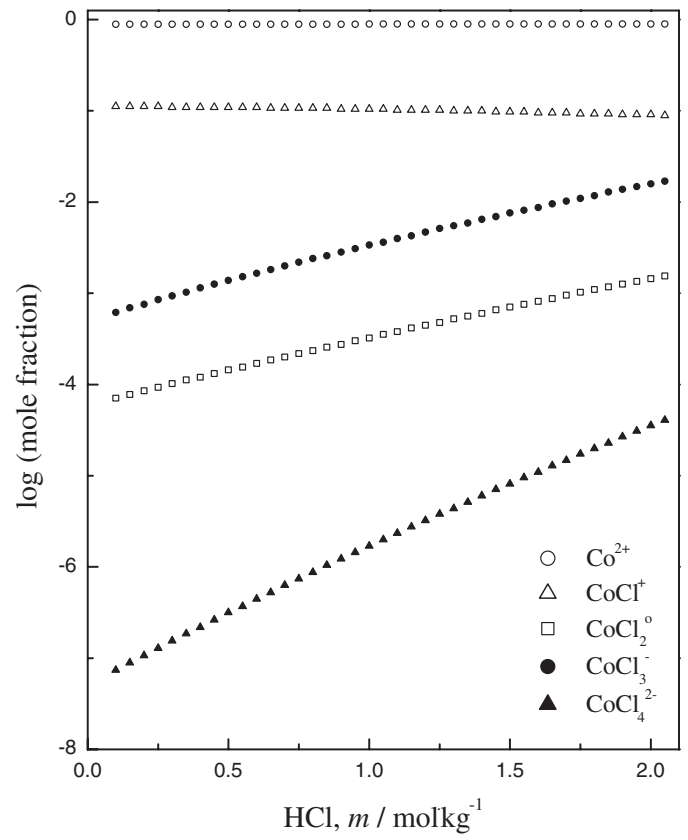

Fig. 4 Distribution of cobalt chloride complexes with $\mathrm{HCl}$ concentration. $\left(\left[\mathrm{CoCl}_{2}\right]_{\mathrm{t}}=1.0 \mathrm{~m}\right)$

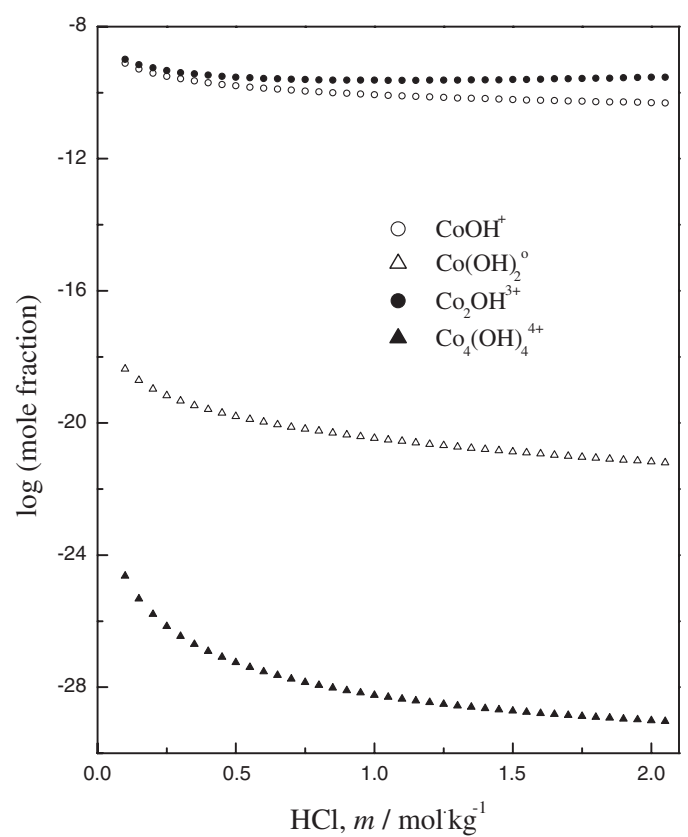

Fig. 5 Distribution of cobalt hydroxide complexes with $\mathrm{HCl}$ concentration. $\left(\left[\mathrm{CoCl}_{2}\right]_{\mathrm{t}}=1.0 \mathrm{~m}\right)$.

and $\mathrm{Co}_{3} \mathrm{OH}^{3+}$ are higher than that of $\mathrm{CoCl}_{4}{ }^{2-}$.

Figures 4 and 5 show the distribution of cobalt chloride and hydroxide complexes with $\mathrm{HCl}$ concentration when $\mathrm{CoCl}_{2}$ concentration was $1.0 \mathrm{~m}$. It is seen in Fig. 4 that most of cobalt exists as $\mathrm{Co}^{2+}$ up to $2.0 \mathrm{~m} \mathrm{HCl}$ concentration. The mole fraction of $\mathrm{CoCl}_{2}{ }^{\circ}, \mathrm{CoCl}_{3}{ }^{-}$and $\mathrm{CoCl}_{4}{ }^{2-}$ increased with $\mathrm{HCl}$ concentration while that of $\mathrm{CoCl}^{+}$remained constant. From Fig. 5, it is known that the mole fraction of cobalt hydroxide complexes was very low in the solution containing $\mathrm{HCl}$. 


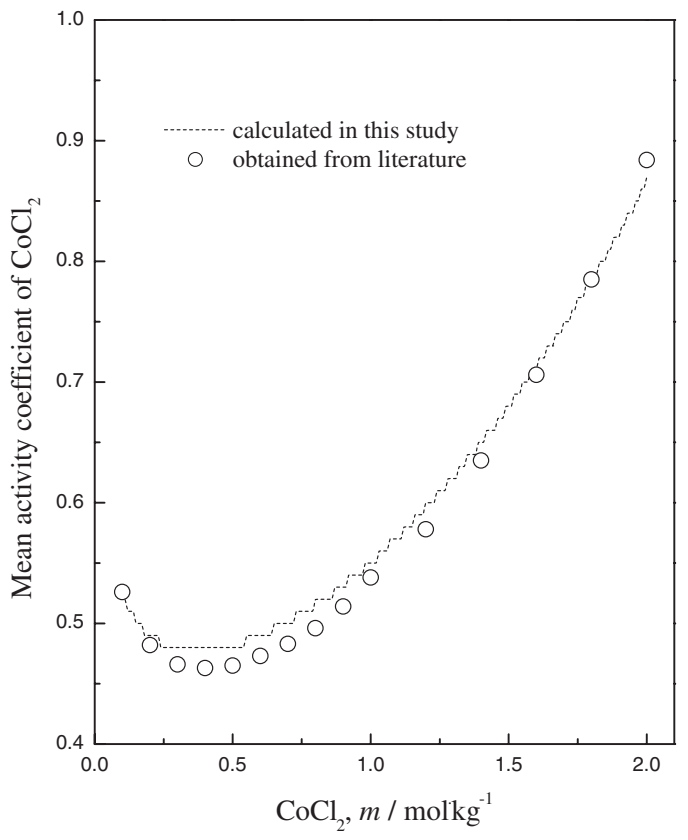

Fig. 6 Variation of the mean activity coefficient of $\mathrm{CoCl}_{2}$ with the concentration of $\mathrm{CoCl}_{2}$.

Mean activity coefficients of $\mathrm{CoCl}_{2}$ were calculated by the following equation from the activity coefficient of $\mathrm{Co}^{2+}$ and $\mathrm{Cl}^{-}$calculated with the Bromley equation.

$$
\gamma_{ \pm, \mathrm{CoCl}_{2}}=\left\{\gamma_{\mathrm{Co}^{2+}}\left(\gamma_{\mathrm{Cl}^{-}}\right)^{2}\right\}^{1 / 3}
$$

Figure 6 shows mean activity coefficients of $\mathrm{CoCl}_{2}$ calculated and those obtained from literature. ${ }^{11)}$

It is seen in Fig. 6 that mean activity coefficients of $\mathrm{CoCl}_{2}$ experimentally measured agreed well with those calculated in this study.

\section{Conclusions}

By considering chemical equilibria, mass and charge balance equations for $\mathrm{CoCl}_{2}-\mathrm{HCl}-\mathrm{NaOH}-\mathrm{H}_{2} \mathrm{O}$ system at $298 \mathrm{~K}$, ionic equilibira were analyzed. The equilibrium constants for the formation of cobalt chloride complexes at zero ionic strength and the interaction parameter were estimated by applying the reported equilibrium constants at different ionic strength to the Bromley equation. The distribution of cobalt complexes with $\mathrm{CoCl}_{2}$ and $\mathrm{HCl}$ concentrations was obtained by applying ionic equilibria. In the experimental ranges up to ionic strength of $8.8 \mathrm{~m}$, the measured and calculated $\mathrm{pH}$ values were in good agreement.

\section{REFERENCES}

1) F. Habashi: Handbook of Extractive Metallurgy, vol. 2 Wiley-VCH, Weinheim (1997) pp. 923-924.

2) K. Sarangi, B. R. Reddy and R. P. Das: Hydrometallurgy 52 (1999) 253-265.

3) N. B. Devi, K. C. Nathsarma and V. Chakravortty: Hydrometallurgy 49 (1998) 47-61.

4) M. S. Lee and G. S. Lee: J. of Korean Inst. of Resources Recycling 12 (2003) 38-45.

5) L. A. Bromley: AIChE Journal 19 (1973) 313-320.

6) E. Högfeldt: Stability constants of Metal-Ion Complexes: Part A. Inorganic ligands, Pergamon, Oxford (1982) p. 209.

7) J. C. Raposo, J. Sanz, G. Borge, M. A. Olazabal and J. M. Madariaga: Fluid Phase Equilibria 155 (1999) 1-19.

8) Y. Belaustegi, M. A. Olazabal and J. M. Madariaga: Fluid Phase Equilibria 155 (1999) 21-31.

9) J. Bjerrum, G. Schwarzenbach and L.G. Sillén: Stability Constants of Metal-ion Complexes, Part II: Inorganic ligands, The Chemical Society, London (1957) p. 97.

10) J. F. Zemaitis, D. M. Clark, M. Rafal and N. C. Scrivner: Handbook of aqueous electrolyte thermodynamics, A publication of the Design Institute for Physical Property Data, NY (1986) p. 602.

11) H. S. Harned and B. B. Owen: The Physical Chemistry of Electrolytic Solutions, Reinhold Publishing Corp., NY (1950) p. 567. 